\title{
Title: Diffusion of Multi-Generational High-Technology Products
}

\begin{abstract}
:
Previous multi-generational product diffusion (MGPD) models were developed based on the diffusion patterns at that time, but may not be adopted in today's cases. By incorporating the effect of customers' forward-looking behaviour, this paper offers a parsimonious and original model that captures the dynamics of MGPD in current high-technology markets. We empirically examine the feasibility of using previous MGPD models and our suggested model to explain the market growth of new products from high-technology industries. The results show that the new model exhibits better curve fitting and forecasting performance than the prior MGPD models in the cases of this study. For marketing researchers, our model and its results suggest customers' forward looking behaviour is perhaps one of the key sales affecting factors that are missing in previous MGPD models in explaining nowadays' cases. For marketing practitioners, this study offers a valuable tool for marketing strategies in high-tech industries.
\end{abstract}

Keywords: diffusion models; multi-generational; high-technology products; forecasting 


\section{INTRODUCTION}

One important field of the study of diffusion phenomena is to understand and predict the purchase demand of new products utilizing diffusion models. At an aggregated level, the purchase behaviour of first-purchase demand usually follows a bell shape curve that will finally decay due to the saturation of market potential (Bass, 1969; Griliches, 1957; Meade and Islam, 1998), that is, the sales curve reaches a peak and decline is expected thereafter. Following the pioneering work of Bass (1969), a number of diffusion models have been proposed to understand the trend of the first-purchase demand. Some introduce new variables such as marketing-mix variables; some apply the model to more complicated contexts such as internet and global diffusion; and a few others use the model to understand specific phenomena such as the saddle effect (Baldridge and Burnham, 1975; Bass, 2004; Geroski, 2000; Mahajan et al., 1990; Mahajan et al., 2000; Meade and Islam, 2006; Peres et al., 2010).

However, successful products in the market are normally substituted by newer generations with advanced attributes that can create new markets, update existing users, and thus repeatedly boost market demand. Examples are abundant, such as TVs (Tsai, 2013b), cellular phones (Anderson et al., 2008), and video game consoles (Cenamor et al., 2013), . The diffusion process of those multi-generational products has its unique attributes, thus cannot be explained by the first-purchase demand models. Therefore, one of the key demanding issues for both academics and practitioners is to understand, model, and predict the sales behaviour of multigenerational products (Bass, 2004; Mahajan et al., 2000; Meade and Islam, 2006; Peres et al., 2010).

Two of the more frequently cited cases in previous MGPD modelling studies are the cases of IBM mainframe machine and PC DRAM shipments. The diffusion curves in the two examples are generally a set of consequent and overlapped bell shape curves, in which one generation starts to decline after its successor is released (see Figure 1). However, in recent years, the product growth pattern may have changed due to changes in the competitive environment and advances in firm level marketing 
strategy. Consider Apple's PC product (iMac) and smartphone product (iPhone), they are some of the most proliferated products in today's market and they both span multiple successive generations. Figure 1 shows that sales of the two products both have an increasing trend. However, the sales curves are no longer overlapped between generations, as the company normally only maintains one generation of its PC product in the market and has different marketing strategies for its smartphone product through time (initially the company only maintained one generation in the market; however, since the release of the product's third generation they allow multiple generations in the market). Furthermore, the pattern of sales trends for the two products changes after each new generation is released to market, for instance, the second generations of both products have an immediate decline after they are released, which does not exhibit the classical bell shape curve (see Figure 1).

INSERT FIGURE 1 HERE

The above two cases show that prior MGPD models are potentially inapplicable for explaining the diffusion of modern day high-technology products. Reflecting the importance of this issue, we proposed the current study with the objective of understanding and modelling the MGPD processes in the context of current markets. This topic is important, because marketing practitioners increasingly demand tools that help to explain and accurately predict the product sales trends, and because marketing researchers are constantly exploring and updating their understanding of the MGPD phenomena. We aim to provide a parsimonious and original model that captures the dynamics of MGPD in the current high-technology markets, and thus benefits both academics and practitioners who are keen to understand the phenomena. .

The remainder of the paper is structured as follows. The next section reviews existing approaches for understanding and modelling MGPD. We then propose a new approach of modelling MGPD that includes a modified cross generation effect combined with the effect of customers' forward looking behaviour. We give 
empirical validation and discussion of the proposed model using sales data of eight high-technology products with diffusion patterns from different industries. Finally, conclusions are provided.

\section{RELATED LITERATURE}

\subsection{Existing MGPD Models}

The phenomena of MGPD are mostly explained and modelled through homogeneous models. The basic concept behind these models is that, the customer base of each product generation changes due to the introduction of newer generations. Although early attempts in this field may have started from Fisher and Pry (1971), the pioneering work is usually credited to Norton and Bass (1987) (the NB model). The key concept embedded in the NB model is that, the later generation plunders the customer base of its earlier generation when they exist in the market simultaneously. As the NB model does not differentiates the leapfrogging and switching adoptions, Jiang and Jain (2012) recently develop a generalised NB model to fill this gap.. Another important contribution in this field is a Bass-type model proposed by Mahajan and Muller (1996) (the MM model). Similar with the NB model, the primary focus of the MM model is the dynamic potential customers of each generation. Differently, the MM model suggests a customer after purchasing one generation of the product will immediately become a potential customer of the following generations through upgrading or leapfrogging. In others words, each generation plunders potential customers from its earlier generation in the NB model; each generation absorb product users from its previous generations as its potential customers in the MM model. Later works such as Speece and Maclachlan (1995), Islam and Meade (1997), Danaher et al. (2001), Kim et al. (2000), Chanda and Bardhan (2008), Stremersch et al. (2010), and (Tsai, 2013a) are more or less inspired by the NB model and the MM model.

Another popular approach of explaining the MGPD process is through choice models. In a simple case, Lattin and Rober (2000) and Kim and Srinivasan (2003) propose their models, in which customers decide to buy a newer version of the product if the expected utility of the new generation is greater than the utility of their current one. 
In a more complicated setting where multi generations of a product exist in the market at the same time, customers evaluate the utility obtained by adopting each generation and the non-purchase utility, and then choose the option that results in the highest utility. Following this understanding, Jun and Park (1999) and Jun et al. (2002) integrate the diffusion effects and choice effects to explain customers' purchase behaviour regarding successive generations of a durable technology (we name it the JP model in this study). This stream of modelling concept is recently adopted in studies such as Kreng and Wang (2009) and Kim and Srinivasan (2009). Besides the above two main streams, some scholars are also exploring other possible approaches of modelling MGPD. For instance, Tsai (2013b) predicts the market growth of generations of LCD TVs with an extended Gompertz model; Kreng and Wang (2013) constructs an MGPD model based on system dynamics for a case of Nike Golf clubs.

MGPD models in the literature are mostly applied to products on the category level such as the cases of PC DRAM and mobile phone technologies, in order to avoid the competition effect between products of different brands. Although the case of IBM mainframe machines is also frequently used, it should be noted that IBM dominated the market of mainframe machines during the studied time period and thus it did not have really strong competitors.

\subsection{Forward-Looking Effect}

Recalling the case of Apple's PC and smartphone products, the sales of one generation sometimes start to decline soon after it is released (even the generation is considered successful, such as the second generation of Apple's smartphone). This suggests a negative driving power that perhaps has not been mentioned in the existing MGPD modelling literature. In a recent study by Decker and Gnibba-Yukawa (2010), five factors are selected as more influential in high-technology product diffusion, namely: democratization of innovation, interpersonal communication, network effect, demand heterogeneity effect, and forward looking effect. Among them, democratization of innovation is normally considered to have a positive influence on diffusion speed; interpersonal communication and network effect need a cumulated user base, therefore do not have much influence on diffusion in the 
initial stage; the demand heterogeneity effect is usually used to explain the saddle effect in diffusion (Goldenberg et al., 2006; Goldenberg et al., 2002; Muller and Yogev, 2006; Van den Bulte and Joshi, 2007); and we consider that the forwardlooking effect has the potential to be a negative driving power in the MGPD processes to explain the above phenomenon - if customers have increasing anticipations towards the next generation, they may stop purchasing the current one.

Customers are likely to form expectations regarding future generations and consequently to use these expectations in their adoption decision (Takeyama, 1994). Combining the understanding of heterogeneity and forward-looking effects, a number of utility-based approaches have been proposed to understand the process of diffusion. These studies are usually based on the following concept: customers at each time point $\mathrm{t}$ will make their adoption decision based on the utility they receive from adopting the product now and the expected utility they receive from adopting the product at $t+1$. However, most of these models are not specifically developed to understand the MGPD problem. For instance, the models of Melnikov (2000), Song and Chintagunta (2003), and Decker and Gnibba-Yukawa (2010) are for one-time purchase products; the model proposed by Erdem et al. (2005) is to understand the phenomena where different products compete with each other; and Prince's Prince (2008) work is to model repeat purchase. One exception here is the study of Namwoon et al. (2002) in which the authors model customers' purchase behaviour towards successive generations of PCs with considerations of product quality of each generation, network externality, customer heterogeneity, and forward-looking effect. However, the model is tailored to understand the small-office / home-office PC market and thus does not provide a valid generalisation. For instance, the model considers the effects of business disposition toward incertitude, which may not be suitable in other product categories.

Therefore, we try to introduce the period of customers' forward looking behaviours in our proposed MGPD model under the context of high-technology markets, in order to see whether this effect is one of the missing pieces from the puzzle. 


\section{MODEL}

\subsection{The Proposed Model}

In the original Bass model (1969), $f(t)$ is defined as the number of customers who buy the product at time $\mathrm{t}$ and $F(t)$ is the cumulative number of buyers, then the product diffusion process within $M$ potential buyers can be explained in Equation 1, where $p$ and $q$ are the parameters of innovation effect (customers decide to purchase the product based on their inner intention) and imitation effect (customers decide the purchase the product based on others' opinions) respectively. Equation 1 is somehow adopted in many influential models to study MGPD phenomena such as the NB model, the MM model, and their extensions. That is, the Bass model is used to outline the initial purchase behaviour of each generation and then crossgeneration effects are added. Our model follows a similar approach. However, it is important to note that the variables and parameters in the Bass-type models can be interpreted with various managerial meanings to fit in different contexts of interest. For instance, parameter $p$ also can be explained as mass media effect, and parameter $q$ can represent the network effect, social contagion effect, and social conformity effect in difference cases (Ansari et al., 2010; Peres et al., 2010); $f(t)$ in the NB model is redefined as customers' knowledge regarding the new products, and it also can be used to describe the probability of customers' adoption behaviour in certain cases.

$$
f(t)=\left(p+\frac{q F(t)}{M}\right)(M-F(t))
$$

We consider a product that has $\mathrm{N}$ successive generations and each generation has better performance than its predecessor. We assume that the customers of each generation do not revert back to earlier generations. For each generation $i$ that is released at time $\tau_{i}$, we let $p_{i}$ and $q_{i}$ be the respective parameters to explain customers who are influenced by the product through innovation and imitation channels; $f_{i}(t)$ be the number of customers who have a positive opinion towards the ith generation and thus have initialised a purchasing intension at time $t$; 
$F_{i}(t)=\sum_{t^{\prime}=1}^{t} f_{i}\left(t^{\prime}\right) ; M_{i}$ be the potential market created by the ith generation. Then we can have Equation 2 following the concept of the Bass model, where $\sum_{t^{\prime}=0}^{t} w_{i-1, i}\left(t^{\prime}\right)$ represents the cumulative number of potential customers who move from previous generation to generation $\mathrm{i}$, due to the cross-generation effect that is proposed in this study and will be discussed in the following paragraph. Note that we have a new definition of $f_{i}(t)$ and $F_{i}(t)$ in the current study. This will be used to differentiate between the adopters who are waiting for the following generation and the adopters who purchase the current generation immediately, due to our proposed cross generation effect. Also note that when the cross-generation effect is not triggered, the model will reduce to the original Bass model, $f$ and $F$ will be the actual number of new adopters and cumulative adopters.

$$
f_{i}(t)=\left(p_{i}+\frac{q_{i} F_{i}(t)}{M_{i}}\right)\left(M_{i}-F_{i}(t)+\sum_{t^{\prime}=0}^{t} w_{i-1, i}\left(t^{\prime}\right)\right)
$$

Now we provide our proposed cross generation effect in this study. We assume that potential customers' initial purchase intension may become uncertain due to the later generation with more advanced functions. Consequently, some customers may decide to prolong their purchase decision and become the potential adopters of the later generation. We choose time as the indicator for the possibility of the potential customers' leapfrogging behaviour, as the longer the current generation has been available in the market, the higher the customer's perception of performance degradation of that generation relative to its successor. Due to the advance of communication channels nowadays, customers usually start to know new generations of products even before they are officially released, especially in the context of the high-technology product markets. Therefore, we assume that customers' adoption decision may have already started to be influenced by the anticipation of future innovative generations before the new generations come to the market (forward-looking behaviour). 
Following the above assumptions, there is a possibility that the customers who have initialised their purchase intention under the influence of the ith generation $\left(f_{i}(t)\right)$ may decide to prolong their purchase decision and further evaluate generation i+1 for more advanced functions. We assume that this possibility will increase through time. Under this setting, there will be a continuous flow of potential customers from generation $\mathrm{i}$ to generation $\mathrm{i}+1\left(w_{i, i+1}(t)\right)$, as shown in Equation 3. In this study, the function $1-\exp \left(-\eta_{i}\left(t-t_{i}^{*}\right)\right)$ is chosen to explain the increased possibility for simplicity. Here, parameter $\eta_{i}\left(\eta_{i} \in[0,+\infty)\right)$ can be considered as a leapfrogging parameter for customers. It is used to explain how likely customers tend to be attracted by the subsequent more advanced generation. $t_{i}^{*}$ is the time point when customers start to be influenced by the later generation. Due to the context of the high-technology product diffusion in this study, we assume that customers start to know or anticipate the following generation soon after the current one is released, and therefore $t_{i}^{*}=\tau_{i}$ unless specified. While in future studies, $t_{i}^{*}$ could vary from case to case due to the characteristics of the studied targets. Also note that when the forward-looking effect is not ignored, the model will reduce to the original Bass model. $f$ and $F$ will be the actual number of new adopters and cumulative adopters.

$$
w_{i, i+1}(t)=f_{i}(t)\left(1-\exp \left(-\eta_{i}\left(t-t_{i}^{*}\right)\right)\right)
$$

Correspondingly, the number of actual buyers of the ith generation $\left(s_{i}(t)\right)$ can be calculated by Equation 4. Note that $f_{i}(t)=s_{i}(t)=w_{i, i+1}(t)=0$, when the generation $\mathrm{i}$ is not officially released; $s_{i}(t)=0, w_{i, i+1}(t)=f_{i}(t)$, if the generation $\mathrm{i}$ is no longer sold in the market, means that all the customers who are influenced by the generation $\mathrm{i}$ will seek to buy generation $\mathrm{i}+1$, as generation $\mathrm{i}$ is no longer available.

$$
s_{i}(t)=f_{i}(t)-w_{i, i+1}(t)
$$




\subsection{Some Further Discussions}

There are several issues regarding the model that need to emphasize here. First, the reason for some customers to prolong their purchase decision is that they are attracted by the potentially more advanced functions of the following generation. Although they become potential customers (or even buyers afterwards) of the following generation, it doesn't mean their positive attitudes and opinions towards the current generation have been changed. In other words, although some customers are likely to choose the more advanced one, they can have positive opinions towards both generations. Therefore, we assume that these customers still exert influence to the potential customers of the current generation, and thus they $\left(\sum_{t^{\prime}=0}^{t} w_{i, i+1}\left(t^{\prime}\right)\right)$ are not excluded from $F_{i}(t)$ in Equation 2.

Second, we consider that the cross generation effects could vary in different contexts, for different products, and across different generations. Hence, the degree of the proposed cross generation effect in the proposed model can vary to represent different MGPD contexts through parameter $\eta_{i}$. In the extreme case when $\eta_{i}=0$, the cross generation effect will vanish. This is different with the settings in most previous MGPD models, as their proposed cross generation effects will always exert influence if more than one generation diffuses in the market simultaneously.

Third, customers in the model are able to leapfrog multi generations. For instance, potential customers of generation i can prolong their purchase decision and become potential customers of generation $\mathrm{i}+1$, then they can further prolong their purchase decision and become potential customers of generation $i+2$, and so forth.

Finally, in this study we do not differentiate the users of each generation into first time users and upgraders. So we define the market potential of each generation as the total number of ultimate value of cumulative sales for the generation, in a similar manner with the study of Jun and Park (1999). In other words, we capture the sum of the two types of market potentials with one single parameter $M_{i}$. 


\section{DATA AND ESTIMATION TECHNIQUE}

\subsection{Data}

In this study, we introduce data from eight products across four companies. These companies represent the relevant high achievement from both technology and market success in today's market and have established a unique reputation in their specialised fields. We obtain the sales data of the products from the annul, interim, or quarterly reports published by the corresponding companies. We divide and discuss the data in two groups. Further details of these data sets also can be found in Table I.

The first group has three companies (Nintendo, Sony, and Microsoft), which together dominate the video game consoles industry. The data we have for Nintendo's Home Console covers three generations; the data of Microsoft and Sony's Home Console both cover two generations; and the data of Sony's Handheld Console we use in the current study only covers one generation. In these data sets, most products' life cycle continue until demand ceases, while the first generation of Microsoft's home console are discontinued before demand ceases. The data of Nintendo and Microsoft Home Consoles are both yearly based and the other two products are based on quarterly data. Also different with the other three, the data of Sony's Home Console are shipments data rather than sales data. All the diffusion curves exhibit a classical diffusion patter (bell shape curve) in most of their generations.

The second group includes one company (Apple Inc.). The company is widely considered as a pioneer in leading the future direction of product development in the consumer electronics industry, and thus its products usually receive high anticipations from customers. The company's best known hardware products include its personal computer (iMac), laptop (MacBook, MacBook pro, MacBook air, etc.), tablet computer (iPad), portable media player (iPod), and smartphone (iPhone). We exclude laptop in this analysis because its laptop product line has a few sub-product lines which make it difficult to categorise generations. For all products in this group, we only have the aggregated sales data (no sales data of each generation). The data of these products are all quarterly based and cover generations ranging from two to 
six. The company normally discontinues the previous generation of a product soon after its successor is released, except in the case of its Smartphone. More interestingly, the sales curves of many products generations show an unusual diffusion pattern than the classical bell shape curves.

INSERT TABLE I HERE

It should be noted that the data we employed in this study are products of brand level, but they have certain unique attributes. Apple's tablet computer, portable media play, and smartphone are monopoly in their respective market during the studied time period. Hence those products rarely faced serious competitions and influences from other brands. Compared with those Windows-based personal computers, Apple's personal computer has its unique and somehow incompatible design regarding both hardware and software, and therefore tend to have its stable customer base. The rest cases are all from video game industry. In particular, not like other types of products that customers mostly have to make one single choice between brands, game players can and usually do purchase more than one consoles. In addition, the video game industry is dominated by very a few firms nowadays, and their products can be easily differentiated regarding product features, functionalities, and their targeted customers.

Moreover, although our suggested model and previous MGPD models do not have an explicit function for the competition effect between products in the same categories, they still have the potential to explain the market growth of certain brand level products. The existing literature usually explains the inter-brand effect on a product's growth from either of the two perspectives: the change (normally enhanced) of the word-of-mouth effect due to the growth of other brands and the change (normally reduced) of the product's market potential due to the penetration of other brands (Peres et al., 2010). Using these MGPD models directly at the brand level naturally assumes that the competition effect on each generation of the product is aggregated, namely, constant through time. We believe the above 
assumption is especially appropriate for today's high-technology products, as each generation only exists for a shorter time in the market. Therefore, the aggregated competition effect (such as the updated word-of-mouth effect and the market potential) on the market growth of each generation can be captured by the existing parameters in these MGPD models. For instance, if one generation of the product faces fierce competition in the market, it is likely to have a reduced market potential. Also we believe the results of the models' empirical applications could implicate the feasibility between the models and the data: if the inter-brand effect is significant in the studied cases, it would be difficult for the models without such effect to fit the observed data.

\subsection{Parameter Estimation}

One key difficulty in implementing this model to fit with real data is the large number of parameters, as the model desires the values of four parameters $p_{i}, q_{i}$, $\eta_{i}$, and $M_{i}$ for each generation. The existing literature shows contradicting views as to whether diffusion rates, specifically, the values of parameters $p$ and $q$ in the Bass model, change across different generations. Some argue that the acceleration rate of diffusion processes across generations should be minimal or non-existent over time; others ascertain that each generation of the product should be considered as an independent item, and thus follows its own diffusion (see Stremersch et al. (2010)). In this study, we adopt the view that parameters $p_{i}$ and $q_{i}$ in the model do not change across generations. It also means that the competition effect discussed in previous section will only be captured by one single parameter $M_{i}$. Furthermore, we assume that, the parameter $\eta_{i}$ also does not change across generations, particularly if the company has a consistent marketing strategy for each product generation (i.e. the time interval between two generations are consistent, the utility incensement between two generations are similar). Therefore, the number of parameters reduces significantly under the above setting. We believe that the above assumption can be easily proved on the basis of model fit, since it will be difficult for the simplified model to fit with real world data, if the values of $p$, $q$, and $\eta$ actually differ across different generations of the same product. 
One issue should be noted here. The data of Apple's smartphone and tablet computer, Sony's Home Console, Sony's Handheld Console, and Microsoft's Home Console used in this study start from their first generation. Customers of the first generation may have no prior knowledge of whether a new generation will be produced, or the time interval between potential new generations. As a result, we assume that customers only started to anticipate the second generations when the company first pre-announced them. In other words, the proposed cross generation effect starts to work on the first generation when the second generation is first preannounced. We denote the first pre-announcement time of the second generation as $\tau_{0}$, thus $t_{1}^{*}=\tau_{0}$. Those first pre-announce data are also given in Table I.

We compare the proposed model with the NB model (Norton and Bass, 1987), the MM model (Mahajan and Muller, 1996), and the JP model (Jun and Park, 1999). For the MM model, in this study we use the modified version of the original MM model proposed by Stremersch et al. (2010). For the JP model, we use the model structure, in which the number of sales for each generation includes both upgraders and firsttime purchasers. The three models are selected as benchmarks due to their wide-use and representativeness in the MGPD literature.

Genetic Algorithm (GA) is used in this study for parameter estimation, as it has a higher probability of reaching the global optimum solution when the targeted model is inherently nonlinear and contains a large number of parameters (Del Moral and Miclo, 2001). We consider a GA tool should be more appropriate in the current study, due to the large parameter numbers and frequent fluctuations in the MGPD models and curves. A performance examination of the GA estimation in diffusion models can be found in the work of Venkatesan et al. (2004). We fit our proposed model and the benchmarks with the actual data in the following ways. For the data sets of those products from video game industry, we estimate the parameters of the proposed model by minimizing the function of $\sum_{t=T_{0}}^{T}\left(\sum_{i=1,2, \ldots}\left(E\left(s_{i}(t)\right)-s_{i}(t)\right)^{2}\right)$, where $s_{i}(t)$ is the actual sales/shipments data of the ith generation of the product and $E\left(s_{i}(t)\right)$ is the data predicted by the model. For the data sets of Apple's products, we estimate the 
parameters of the proposed model by minimizing the function of $\sum_{t=T_{0}}^{T}(E(s(t))-s(t))^{2}$ (where $s(t)$ is the actual aggregated sales data of the product and $E(s(t))$ is the aggregated sales data predicted by the model), as we only have the aggregated sales data of these products, but not the sales data of each individual generation.

The software MatLab is used to compute the GA estimation results. We ran the GA tool with the following settings. The population size of the estimation is set as 200 (200 sample solution vectors are generated for each iteration). The probability of crossover and mutation is set at the software's default value. The stopping rule for estimation is as follows: terminate if there is no improvement (less than 1E-06) in the objective function for 100 consecutive generations. We run the GA estimation for each model of each case 100 times repeatedly. The reported values in this study are the ones that produce the best fit from the 100 repeats of the GA estimation and the standard deviation of the 100 estimates obtained from the repeats. The standard error and $p$-value of each parameter can be calculated correspondingly based on the mean value and standard deviation from the repeats.

\section{RESULTS AND DISCUSSIONS}

\subsection{Results of Model Fit}

A graphical representation of the model's fit with the actual data of the eight products from the video game industry and Apple Inc. is provided in Figure 2. We use five measures of descriptive performance: sum of squared errors of prediction (SSE), mean absolute deviation (MAD), mean absolute percentage error (MAPE), root mean square error (RMSE), R squared $\left(R^{2}\right)$, and adjusted R squared. In particular, adjusted $R^{2}$ is introduced to assess the models' performance with consideration of the number of model parameters. Table II shows the statistical results of the estimations and Table III reports the estimated parameter values of each model. Among these cases, some of them can be explained by all of the four models with different degrees of accuracy, while other product diffusion curves can only be explained by 
some of the models. The following discussions examine the fit of the proposed model and the three benchmarks, respectively.

INSERT FIGURE 2 HERE

INSERT TABLE II HERE

INSERT TABLE III HERE

In general, the proposed model is able to explain all the diffusion trends with good fit. It ranks first in six cases, and scores second in the remaining two. Specifically, the proposed model has a better performance in the cases of Nintendo Home Console, Sony Home Console, Sony Handheld Console, Microsoft Home Console, and Apple's Tablet computer; it has a similar performance with the JP model in the case of Apple's Portable Media Player; and it performs slightly worse than the JP model in the cases of Apple's smartphone product and PC product. Note that these results are based on the proposed model's assumption of constant diffusion parameters $p, q$, and $\eta$ for all generations. Therefore, the JP model has one more parameters to calibrate the curve for each generation than the proposed model. Therefore, the JP model is likely to be more capable in explaining the MGPD processes in which the diffusion patterns vary significantly across generations, such as the cases of Apple's PC and Smartphone. However, the proposed model outperforms the JP model if we relax the assumption and make its diffusion parameters become heterogeneous across generations. The corresponding results are given in Table II and Figure 3, where the proposed model I and the proposed model II denote the proposed model with a relaxed assumption. Especially in the case of Apple's Smartphone product, the curve produced by the proposed model II almost coincides with the observed data. 
INSERT FIGURE 3 HERE

The NB model fails to depict the sales trends of five products: Nintendo Home Console, Sony Home Console, Sony Handheld Console, Apple's PC, and Apple's Portable Media Player. All these product curves share one same pattern, that is one or a few generations of the products start to decline before the following generations are officially released. The NB model does not explain well this type of MGPD processes, as the model is initially designed for repeated purchases, and thus the sales of one generation in the NB model start to decline only because its customer base has been plundered by its actually released successor. In the remaining three products, the NB model also has a comparatively poor performance than the other models. Additionally, in the cases of Microsoft Home Console and Apple's Smartphone, although the model's statistical results look fair (i.e. the reported $\mathrm{R}$ square values are 0.9302 and 0.9675$)$, it cannot explain the turning points in the curves, such as the ninth data point in the case of Microsoft Home Console; and data points three, six, eleven, and seventeen in the case of Apple's Smartphone (see Figure 2).

The MM model's fitting performance ranks second in three cases, third in three cases, forth in one case, and fails to explain the case of Apple's Portable Media Player. Although the MM model can explain the basic curves of most cases in this study, it is unable to depict the trends and turning points of specific generations of certain cases in an accurate manner, such as the examples of Microsoft Home Console and Apple's Smartphone that are mentioned in previous paragraph.

The JP model has very good fitting performance in all cases. It performs well in all Apple's products, especially in the cases of Apple's smartphone product and Apple's PC product. However, as discussed earlier, the JP model's best performance in these two cases is based on the proposed model's assumption of constant diffusion parameters across generations. The JP model's fitting performance is relatively poor in the case of Sony's Home Console, as it basically fails to explain the general trend for the first generation of the product (see Figure 2). 
Note that several of the reported parameters are not statistically significant (see Table III). We see that the reported value of those insignificant parameters all tend to approach 0 . Therefore, we argue that it is because the GA tool under the current setting of this study may not be sensitive enough for those minimal values. We conduct a new experiment to further support our argument. i.e., we run the selected cases again with a more sensitive setting of the GA tool, in order to see if it can produce significant results for those previously insignificant parameters (see results in Table III). However, it should be noted that the new setting of the GA tool does not increase the models' fitting and predictive performance in a visible manner, but sacrifices much time of computing.

\subsection{Some Further Discussions on Model Fit}

There are a few more issues that need to be emphasized here. (1) We define the generations of Apple's PC product based on the major changes of its design, while in each generation of the product the company also provides a number of hardware updates, such small incremental changes are not captured by the models or considered to constitute a new generation; (2) The cases of Sony's Home and Handheld consoles may be influenced by seasonal effects that are not considered in this study, which again results in those fluctuations that are not captured by the models; (3) Apple's portable media player may also be influenced by seasonal effects. However, the company normally chooses high sale seasons to release their new generations of Portable Media Player, which means the life cycle of seasonal effects is consistent with the life cycle of the product generations. Therefore, the JP model and the proposed model can actually explain the sales trends very well even without including seasonal effect factors; (4) The products from the video game industry could be influenced by very strong network effect, that is, the sales of consoles depend on the availability of games that can be used with the consoles (Maruyama and Ohkita, 2011; Zhu and Iansiti, 2012). Here the network effect and our proposed forward looking effect will result in opposite impacts on the product growth: customers' purchase intension towards the current generation will gradually increase due to the increase of available games and gradually decrease due to the forward looking behaviour. This might be the key reason for the low value of 
parameter $\eta$ reported in some of the video console products. However, it from the another perspective suggests the importance of the forward looking effect, as the forward looking effect is one of the few effects that can counteract the strong network effect here; (5) The products face different level of competitions in their respective markets. The three home console products from the video game industry are direct competitors with each other. Some of Apple's products such as Portable Media Player and Tablet Computer have been the market leaders in their respective fields. Apple's other products also have their solid customer base due to the company's reputation. We show the performance of the MGPD models in explaining these cases. For instance, Nintendo's GameCube is less successful in the market than its predecessor (N64) due to its relative low product utility than its major competitors (Sony's PlayStation 2 and Microsoft's Xbox). Our suggested model, the MM model, and the JP model are all capable to explain GameCube's market growth through a low value of the estimated market potential, indicating that many of Nintendo's potential customers switch to Sony and Microsoft's products.

To sum up, our suggested model has the best performance among the four models from an overall view. The JP model is also capable to explain the cases with this study in an accurate manner. The NB model and the MM model, however, perform less well and even fail to explain some of the cases.

\subsection{Forward Looking Effect}

The proposed model is developed on the basis of the Bass model, and thus is perhaps more close and comparable to the NB model and the MM model regarding the model structure. Our model has an extended cross-generation effect that includes the period of customers' forward looking behaviour, which is the main difference compared with the other two models.

Due to the consideration of the forward looking effect, the proposed model is capable to capture the trends as well as those turning points in the curves that are not captured by the NB model and the MM model. For certain generations of Apple's products, their sales start to drop down soon after they are released. This phenomenon can hardly be explained by the NB model or the MM model, but can be 
easily explained by the introduction of the forward-looking effect proposed in the current model, that is, customers prefer to purchase the products when they are new to the market, otherwise they will become likely to wait until the next new generation is released. Especially in those Apple's products, the results show that the parameter $\eta$ is statistically significant with very high values. For instance, $\eta=0.2631$ (in the case of Apple's smartphone) means that, $23.13 \%$ $(1-\exp (-0.2631 \times 1)=0.2313)$ of those customers who are influenced by the current generation will decide to wait for the following generation after one time interval, and the figure will increase to $40.92 \%$ and $54.58 \%$ after two and three time intervals. Therefore, our results suggest an important role of the proposed forward looking effect in these cases. It is also consistent with the fact that Apple's new products are usually anticipated by customers and thus have strong influence to customers' current purchase decisions.

The model structure of the JP model and the proposed model cannot be compared directly as they are based on different streams of MGPD modelling concepts. From the statistical results of the model fitting performance, although the JP model also can explain the curves of all products well, its overall performance is worse than the proposed model. Therefore, we conclude that the forward looking effect could be one important and missing factor in previous MGPD models for explaining today's high-technology product diffusion, at least in the models that are derived from concept of the NB model and the MM model.

\subsection{Models' Forecasting Performance}

In order to examine the predictive validity of the proposed model, we compare our model with the NB model, the MM model, and the JP model using the same data sets in Table I. We first divide each data set into the calibration period (CP) and the forecasting period. Then the data in the CPs are used to estimate the model parameters in order to predict the data in the forecasting periods. Similar with many other MGPD works in the literature, we examine the models' ability of forecasting the diffusion trend for the last generation, no matter how many generations are available. Our way of analysis is defined as follows: 
1. We assume that each data set has $T$ data points and $G$ generations, the last generation has $\mathrm{T}_{\mathrm{G}}$ data points;

2. We start from using the first $T-T_{G} / 2$ data points as the $C P\left(T_{C P}\right)$, thus $T_{C P}=T-T_{G}$ $/ 2$; in other words, we start to predict the sales data from the half way of the last generation;

3. By using the data set in the $\mathrm{CP}$, we estimate the corresponding parameter values in the models and predict the value of data point at $T_{C P}+1, T_{C P}+2, \ldots$, and, $T$;

4. We then add one more data point into the $C P\left(T_{C P}=T_{C P}+1\right)$ and repeat 3 , until we terminate at $\mathrm{T}_{\mathrm{CP}}=\mathrm{T}$;

5. Finally, we sum the forecasting results of each model in each product as its overall forecasting performance for the product.

6. Note: for the cases of Sony Home Console and Handheld Console, as their sales curves may be influenced by the seasonal effects, we group the consequent four data points together to form the yearly data in the prediction in order to reduce the influence of the seasonal effects. For instance, in the case of Sony Handhold Console, we first use the initial 14 data points as CP to predict the sales from 15 to 18 as a whole and the sales from 19 to 22 as whole; then we use the initial 18 data points as CP to predict the sales from 19 to 22 as a whole.

In Table IV, we report the forecasting performance using the MAPE indicator that results from a comparison of the forecasts with the actual sales for all models.

INSERT TABLE IV HERE

The results show that the models' forecasting performance varies in different products, with different CPs, and for different points ahead forecasting. However, it is clear that the proposed model's overall forecasting performance is superior among the four. Specifically, the model can predict the basic trends as well as the turning points in most cases; it performs especially better in the case of Apple's PC and Smartphone products, Nintendo Home Console, and Sony's Home Console; it has similar performance with the JP model in the cases of Apple's Tablet Computer and 
Portable Media Player, and similar performance with the MM model in the case of Sony's Handheld Console (all slightly better according to the reported results in this study); while it has a relatively poor performance in the case of Microsoft Home Console.

The turning point of the first generation of Microsoft Home Console comes after one time interval, while the turning point of the second generation comes after three time intervals. Due to the limited data and inconsistent diffusion patterns across generations, the proposed model (as well as the JP model and the MM model) always prematurely predicts the turning points and thus result in bias. One issue should be noted here, although the NB model has a relatively better forecasting performance in this case, it cannot predict the turning point in the sales curve. See Figure 4, the NB model does not predict the turning point of the sales trend that comes at the ninth data point, but all the other models do. Therefore, whether the performance of the NB model is the best in the case of Microsoft Home Console is questionable.

INSERT FIGURE 4 HERE

Both the NB model and the MM model are not capable to act as a workable forecasting aid to be applied in all the cases of this study. As the NB model even fails to do the model fitting in some of the products, we do not report its forecasting results in those cases (Nintendo Home Console, Sony Home Console, Apple's PC, and Apple's Portable Media Player). Under the same reason, we do not report the forecasting performance of the MM model from the case of Apple's Portable Media Player. Although the JP model performs well in the model fitting test, it turns out to have a relatively poor forecasting ability. It ranks second in the cases of Microsoft Home Console and Apple's Portable Media Player, and third in the remaining five cases. 


\section{CONCLUSIONS}

Most successful products have successive generations, especially in today's hightechnology markets. It is critical for firms to understand, monitor, and predict the MGPD process, in order to possess a competitive advantage over its rivals. This paper offers a plausible and original model that captures the dynamics of successive product growth reflecting today's high-technology markets. The empirical analysis shows that the proposed model has the best model fit with the high-technology products in today's market, followed by the JP model, the MM model, and the NB model.

\section{Implications}

This study offers several important implications to both theory and practice. First, the drivers of diffusion are constantly changing due to the change of the market and firm level marketing strategies. Meanwhile, new products in today's market are exposed to more influences than ever before. Our study examines three representative MGPD models from the existing literature using data from eight products across different companies. The reported model performance varies in different cases. More importantly, the study shows that previous MGPD models are not applicable for certain products in today's high-technology market. The results imply both researchers and practitioners to pay more attentions on the selection of MGPD models in studying new products.

Second, our study suggests the forward-looking effect is perhaps one of the key missing elements in previous MGPD models in explaining the current cases. Customers may have strong anticipations towards future generations of a product and thus decide to leapfrog current generation. In extreme cases, customers will quickly lose purchase interest after the release of one generation, and start to wait for the following one. Therefore, the market growth of recent multi-generational products sometimes exhibit an immediate sales decline after the release of one generation. Our empirical analysis shows that such MGPD phenomena can be more accurately explained by the MGPD model incorporating forward looking effect. 
Third, in agreement with Kok and Biemans (2009) and Pérez-Luño and Cambra (2013), this work implies firms to learn about and anticipate customer needs. That is, in high-technology practice the predicted market growth of multi-generational products and the corresponding marketing strategies should be adjusted depending on the level of customers' forward looking behaviour. Through incorporating forward looking effect into the new model for studying MGPD, the results of this study can serve as a valuable reference for marketing strategies in the relevant industries.

Last but not least, the new model can be considered as a valuable tool for predicting the market performance of new products in a wide range of high-technology practice. The issues regarding the market growth of high-tech products have been a hot area in the innovation and management literature (Bridges et al., 1995; Decker and Gnibba-Yukawa, 2010; Goldenberg et al., 2006; Jain et al., 1998; Norton and Bass, 1987). Similar with those works, the data we adopt in the current study are from: the computing industry (personal computers and laptops); the mobile phone industry (smartphone); the home entertainment industry (video game console); and the audio industry (portable media player). These data sets cover a wide range of possibilities: the data length ranges from 8 data points to 50 data points; the number of generations range from 1 to 6 ; the data types include both sales data and shipment data; the data intervals cover both yearly data and quarterly data; the cross generation effect in these data sets are also varied from case to case according to the model estimation results. Except from the cases we used in this study, we believe the proposed model has extensive application possibilities to other product categories.

\section{Research Limitations}

This research has a few limitations. First, our model uses one equation to explain the cross generation effect before and after new generations are released. In reality, customers' anticipation and perception of new generations could be changed after the new generations are actually released, which would results in different cross generation effects in the two periods. Second, our model uses time as the only factor in modelling the forward looking effect and consequently the cross generation effect. 
This could be extended to include other factors such as product price and product utility. Correspondingly, parameter $\eta_{i}$ will be a vector of parameters of those factors. Third, our model does not explicitly consider phenomena such as the inter-product competition, customers leapfrogging multi generations, and the distinction between upgraders and first-time purchasers. Although we give corresponding discussions in this study, we believe these issues need to be further complemented by future works. Finally, we use GA as the parameter estimation technique. Although the models' performance may be slightly different if other techniques are used, we believe that the results produced by other estimation techniques will not change the main findings of this study, as the proposed model in many cases performs significantly better than the benchmarks. However, an examination for the best MGPD model estimation technique would be needed. 


\section{REFERENCES}

Anderson, T.R., Daim, T.U., Kim, J., 2008. Technology forecasting for wireless communication. Technovation 28, 602-614.

Ansari, S.M., Fiss, P.C., Zajac, E.J., 2010. Made To Fit: How Practices Vary As They Diffuse. The Academy of Management Review 35, 67-92.

Baldridge, J.V., Burnham, R.A., 1975. Organizational Innovation: Individual, Organizational, and Environmental Impacts. Administrative Science Quarterly 20, 165-176.

Bass, F.M., 1969. A New Product Growth for Model Consumer Durables. MANAGEMENT SCIENCE 15, 215-227.

Bass, F.M., 2004. Comments on "A New Product Growth for Model Consumer Durables": The Bass Model. MANAGEMENT SCIENCE 50, 1833-1840.

Bridges, E., Yim, C.K., Briesch, R.A., 1995. A High-Tech Product Market Share Model with Customer Expectations. Marketing Science 14, 61-81.

Cenamor, J., Usero, B., Fernández, Z., 2013. The role of complementary products on platform adoption: Evidence from the video console market. Technovation 33, 405-416.

Chanda, U., Bardhan, A.K., 2008. Modelling innovation and imitation sales of products with multiple technological generations. The Journal of High Technology Management Research 18, 173-190.

Danaher, P.J., Hardie, B.G.S., Putsis, W.P., Jr., 2001. Marketing-Mix Variables and the Diffusion of Successive Generations of a Technological Innovation. Journal of Marketing Research 38, 501-514.

Decker, R., Gnibba-Yukawa, K., 2010. Sales Forecasting in High-Technology Markets: A Utility-Based Approach. Journal of Product Innovation Management 27, 115-129.

Del Moral, P., Miclo, L., 2001. Asymptotic Results for Genetic Algorithms with Applications to Nonlinear Estimation, in: Kallel, L., Naudts, B., Rogers, A. (Eds.), Theoretical Aspects of Evolutionary Computation. Springer-Verlag, Berlin, Germany, pp. 439-494.

Erdem, T., Keane, M.P., Öncü, T.S., Strebel, J., 2005. Learning About Computers: An Analysis of Information Search and Technology Choice. Quantitative Marketing and Economics 3, 207-247.

Fisher, J.C., Pry, R.H., 1971. A simple substitution model of technological change. Technological Forecasting and Social Change 3, 75-88.

Geroski, P.A., 2000. Models of technology diffusion. Research Policy 29, 603-625.

Goldenberg, J., Barak, L., Muller, E., Peres, R., 2006. Blazing Saddles: the Early and Mainstream Markets in the High-tech Product Life Cycle. Israel Economic Review 4, 85-108.

Goldenberg, J., Libai, B., Muller, E., 2002. Riding the Saddle: How Cross-Market Communications Can Create a Major Slump in Sales. The Journal of Marketing 66, 1-16. 
Griliches, Z., 1957. Hybrid Corn: An Exploration in the Economics of Technological Change. Econometrica 25, 501-522.

Islam, T., Meade, N., 1997. The Diffusion of Successive Generations of a Technology: A More General Model. Technological Forecasting and Social Change 56, 49-60.

Jain, N., Mahajan, V., Matsuo, H., 1998. When should you not target the entire potential market of a high-technology product with a short life cycle?, University of Texas at Austin.

Jiang, Z., Jain, D.C., 2012. A Generalized Norton-Bass Model for Multigeneration Diffusion. MANAGEMENT SCIENCE 58, 1887-1897.

Jun, D.B., Kim, S.K., Park, Y.S., Park, M.H., Wilson, A.R., 2002. Forecasting telecommunication service subscribers in substitutive and competitive environments. International Journal of Forecasting 18, 561-581.

Jun, D.B., Park, Y.S., 1999. A Choice-Based Diffusion Model for Multiple Generations of Products. Technological Forecasting and Social Change 61, 45-58.

Kim, N., Chang, D.R., Shocker, A.D., 2000. Modeling Intercategory and Generational Dynamics for a Growing Information Technology Industry. MANAGEMENT SCIENCE 46, 496512.

Kim, S.-H., Srinivasan, V., 2003. A Multiattribute Model of the Timing of Buyers' Upgrading to Improved Versions of High Technology Products. Graduate School of Business.

Kim, S.-H., Srinivasan, V., 2009. A Conjoint-Hazard Model of the Timing of Buyers' Upgrading to Improved Versions of High-Technology Products*. Journal of Product Innovation Management 26, 278-290.

Kok, R.A.W., Biemans, W.G., 2009. Creating a market-oriented product innovation process: A contingency approach. Technovation 29, 517-526.

Kreng, V.B., Wang, B.J., 2013. An innovation diffusion of successive generations by system dynamics - An empirical study of Nike Golf Company. Technological Forecasting and Social Change 80, 77-87.

Kreng, V.B., Wang, H.T., 2009. A technology replacement model with variable market potential - An empirical study of CRT and LCD TV. Technological Forecasting and Social Change 76, 942-951.

Lattin, J.M., Rober, J.H., 2000. The Application of an Individual Level Diffusion Model Prior to Launch. Stanford University.

Mahajan, V., Muller, E., 1996. Timing, diffusion, and substitution of successive generations of technological innovations: The IBM mainframe case. Technological Forecasting and Social Change 51, 109-132.

Mahajan, V., Muller, E., Bass, F.M., 1990. New Product Diffusion Models in Marketing: A Review and Directions for Research. The Journal of Marketing 54, 1-26.

Mahajan, V., Muller, E., Wind, Y., 2000. New-Product Diffusion Models. Kluwer Academic Press, Boston \& Dordrecht. 
Maruyama, M., Ohkita, K., 2011. Platform strategy of video game software in Japan, 19841994: theory and evidence. Managerial and Decision Economics 32, 105-118.

Meade, N., Islam, T., 1998. Technological Forecasting -- Model Selection, Model Stability, and Combining Models. MANAGEMENT SCIENCE 44, 1115-1130.

Meade, N., Islam, T., 2006. Modelling and forecasting the diffusion of innovation - A 25-year review. International Journal of Forecasting 22, 519-545.

Melnikov, O., 2000. Demand for Differentiated Durable Products: The Case of the U.S. Computer Printer Market. Yale University.

Muller, E., Yogev, G., 2006. When does the majority become a majority? Empirical analysis of the time at which main market adopters purchase the bulk of our sales. Technological Forecasting and Social Change 73, 1107-1120.

Namwoon, K., Han, J.K., Srivastava, R.K., 2002. A Dynamic IT Adoption Model for the SOHO Market: PC Generational Decisions with Technological Expectations. MANAGEMENT SCIENCE 48, 222-240.

Norton, J.A., Bass, F.M., 1987. A Diffusion Theory Model of Adoption and Substitution for Successive Generations of High-Technology Products. MANAGEMENT SCIENCE 33, 10691086.

Peres, R., Muller, E., Mahajan, V., 2010. Innovation diffusion and new product growth models: A critical review and research directions. International Journal of Research in Marketing 27, 91-106.

Pérez-Luño, A., Cambra, J., 2013. Listen to the market: Do its complexity and signals make companies more innovative? Technovation 33, 180-192.

Prince, J.T., 2008. Repeat Purchase amid Rapid Quality Improvement: Structural Estimation of Demand for Personal Computers. Journal of Economics \& Management Strategy 17, 1-33.

Song, I., Chintagunta, P.K., 2003. A Micromodel of New Product Adoption with Heterogeneous and Forward-Looking Consumers: Application to the Digital Camera Category. Quantitative Marketing and Economics 1, 371-407.

Speece, M.W., Maclachlan, D.L., 1995. Application of a Multi-Generation Diffusion Model to Milk Container Technology. Technological Forecasting and Social Change 49, 281-295.

Stremersch, S., Muller, E., Peres, R., 2010. Does new product growth accelerate across technology generations? Marketing Letters 21, 103-120.

Takeyama, L.N., 1994. The Welfare Implications of Unauthorized Reproduction of Intellectual Property in the Presence of Demand Network Externalities. The Journal of Industrial Economics 42, 155-166.

Tsai, B.-H., 2013a. Modeling diffusion of multi-generational LCD TVs while considering generation-specific price effects and consumer behaviors. Technovation In Press.

Tsai, B.-H., 2013b. Predicting the diffusion of LCD TVs by incorporating price in the extended Gompertz model. Technological Forecasting and Social Change 80, 106-131. 
Van den Bulte, C., Joshi, Y.V., 2007. New Product Diffusion with Influentials and Imitators. Marketing Science 26, 400-421.

Venkatesan, R., Krishnan, T.V., Kumar, V., 2004. Evolutionary Estimation of Macro-Level Diffusion Models Using Genetic Algorithms: An Alternative to Nonlinear Least Squares. Marketing Science 23, 451-464.

Zhu, F., lansiti, M., 2012. Entry into platform-based markets. Strategic Management Journal 33, 88-106. 
Table I: Data

\begin{tabular}{|c|c|c|c|c|c|c|c|c|}
\hline Company & Product & Data & \multicolumn{6}{|c|}{ Generations Used in This Study } \\
\hline \multirow[b]{2}{*}{ Nintendo } & \multirow[b]{2}{*}{$\begin{array}{l}\text { Home } \\
\text { Console }\end{array}$} & \multirow[b]{2}{*}{$\begin{array}{l}\text { Yearly data; } \\
15 \text { data points } \\
\text { Range: } 1997-2011\end{array}$} & \multicolumn{2}{|c|}{ N64 } & \multicolumn{2}{|c|}{ GameCube } & \multicolumn{2}{|c|}{ Wii } \\
\hline & & & \multicolumn{6}{|c|}{$\begin{array}{l}\text { - } 15 \text { data points are used; } \\
\text { - We have the sales data of the most recent three generations of the product. The first data point is used as } \\
\text { the initial input of the models, as the sales data of N64 before } 1997 \text { is not available in the current study; }\end{array}$} \\
\hline \multirow{4}{*}{ Sony } & \multirow[b]{2}{*}{$\begin{array}{l}\text { Home } \\
\text { Console }\end{array}$} & \multirow[b]{2}{*}{$\begin{array}{l}\text { Quarterly data; } \\
50 \text { data points } \\
\text { Range: } 1994-2006\end{array}$} & \multicolumn{3}{|c|}{ PlayStation } & \multicolumn{3}{|c|}{ PlayStation 2} \\
\hline & & & \multicolumn{6}{|c|}{$\begin{array}{l}\text { - } 50 \text { data points are used; } \\
\text { - The monthly shipment data of PlayStation is available from } 1998 \text { to 2006, covering two generations; } \\
\text { - PlayStation } 3 \text { is not considered in the current study due to the lack of its shipment data; } \\
\text { - PlayStation is the first generation of this product line; PlayStation } 2 \text { was first pre-announced in 1999; }\end{array}$} \\
\hline & \multirow[b]{2}{*}{$\begin{array}{l}\text { Handheld } \\
\text { Console }\end{array}$} & \multirow[b]{2}{*}{$\begin{array}{l}\text { Quarterly data; } \\
22 \text { data points } \\
\text { Range: } 2006-2011\end{array}$} & \multicolumn{6}{|c|}{ PSP } \\
\hline & & & \multicolumn{6}{|c|}{$\begin{array}{l}\text { - } 22 \text { data points are used; } \\
\text { - We consider the first generation of Sony's handheld console product line, as the data of the second } \\
\text { generation is too little to consider; } \\
\text { - PSP's successor, PSP vita was first pre-announced in July 2009, and was released in December, 2011; }\end{array}$} \\
\hline \multirow[b]{2}{*}{ Microsoft } & \multirow[b]{2}{*}{$\begin{array}{l}\text { Home } \\
\text { Console }\end{array}$} & \multirow[b]{2}{*}{$\begin{array}{l}\text { Yearly data; } \\
10 \text { data points } \\
\text { Range: } 2001-2011\end{array}$} & \multicolumn{3}{|c|}{ Xbox } & \multicolumn{3}{|c|}{ Xbox 360} \\
\hline & & & \multicolumn{6}{|c|}{$\begin{array}{l}\text { - } 10 \text { data points are used; } \\
\text { - We consider the all two generations of Microsoft's Xbox product line; } \\
\text { - Xbox is the first generation of this product line; Xbox } 360 \text { was first pre-announced in 2003; } \\
\text { - Xbox discontinued after Xbox } 360 \text { was released in the market; } \\
\text { - All the models' predicted data overestimate the sales data of Xbox for the year 2001, as Xbox was just } \\
\text { released in November of the year. Therefore, we divide the models' initially predicted sales of year } 2001 \text { by } 4 \\
\text { as the models' predicted sales for that year. The logic is that the last quarter of the year normally take } 1 / 3 \text { of } \\
\text { the whole year's sales of Video Game Home Console (calculated from PlayStation data), and roughly the } \\
\text { most sales in each year's last quarter are during the end of the year (Christmas); }\end{array}$} \\
\hline \multirow{8}{*}{ Apple } & \multirow[b]{2}{*}{ Smartphone } & \multirow[b]{2}{*}{$\begin{array}{l}\text { Quarterly data; } \\
18 \text { data points } \\
\text { Range: } 2007-2011\end{array}$} & iPhone & \begin{tabular}{l|l} 
& \\
\end{tabular} & hone 3G & iPhone 3 & 年 & Phone 4 \\
\hline & & & \multicolumn{6}{|c|}{$\begin{array}{l}\text { - } 18 \text { data points are used; } \\
\text { - We use the data of Apple smartphone that covers four generations; } \\
\text { - iPhone is the first generation of this product line; the second generation, iPhone } 3 G \text { was first pre-announced } \\
\text { in June 2008; } \\
\text { - iPhone discontinued after iPhone } 3 G \text { was released; iPhone } 3 G \text { discontinued after iPhone } 4 \text { was released; }\end{array}$} \\
\hline & \multirow[b]{2}{*}{$P C$} & \multirow[b]{2}{*}{$\begin{array}{c}\text { Quarterly data; } \\
53 \text { data points }{ }^{a} ; \\
\text { Range: } 1999-2011\end{array}$} & G3 & G4 & G5 & Intel Plastic & Aluminium & $\begin{array}{c}\text { Aluminium } \\
\text { Unibody }\end{array}$ \\
\hline & & & \multicolumn{6}{|c|}{$\begin{array}{l}\text { - } 49 \text { data points are used; } \\
\text { - We use the data from the fifth data point, as it represents the starting point of a new generation; Therefore, } \\
\text { only } 49 \text { data points are actually used; } \\
\text { - The sales data of iMac we have in the analysis is from 1999, that include six generations; } \\
\text { - The generations of iMac are mainly characterized by the majors change on its design, but not hardware } \\
\text { - Wpdates; }\end{array}$} \\
\hline & \multirow[b]{2}{*}{$\begin{array}{l}\text { Portable } \\
\text { Media } \\
\text { Player }\end{array}$} & \multirow[b]{2}{*}{$\begin{array}{l}\text { Quarterly data; } \\
36 \text { data points } \\
\text { Range: } 2002-2011\end{array}$} & iPod Classic 5G & $\begin{array}{l}\text { iPod Shuffle 2G } \\
\text { iPod Nano 2G }\end{array}$ & $\begin{array}{l}\text { iPod Classic 6G } \\
\text { iPod Nano 3G } \\
\text { iPod Touch 1G }\end{array}$ & $\begin{array}{l}\text { iPod Nano 4G } \\
\text { iPod Touch 2G }\end{array}$ & $\begin{array}{l}\text { iPod Nano 5G } \\
\text { iPod Touch 3G }\end{array}$ & $\begin{array}{c}\text { iPod Shuffle 4G } \\
\text { iPod Nano 6G } \\
\text { iPod Touch 4G }\end{array}$ \\
\hline & & & \multicolumn{6}{|c|}{$\begin{array}{l}\text { - } 24 \text { data points are used; } \\
\text { - We exclude the data before } 2005 \text { in the analysis, since (1) the product was in the take-off stage during the } \\
\text { period of } 2002-2004 ; \text { (2) the company release a new model of iPod every quarter in 2005, resulting too } \\
\text { many generations to consider. Therefore, only } 24 \text { data points are actually used; } \\
\text { - iPod has many lines of products and each of them has a few generations. After 2005, the company starts to } \\
\text { release a new version of each product line at the same time, which makes it easier to define generations of } \\
\text { iPod; } \\
\text { - We consider that new generations of iPod are released in the last quarter of each year after 2005, although } \\
\text { the actual data is September of each year, because September is already the end of the third quarter. } \\
\text { - Each generation of Apple's Portable Media Player discontinues after its successor is released in the market; }\end{array}$} \\
\hline & \multirow[b]{2}{*}{$\begin{array}{c}\text { Tablet } \\
\text { Computer }\end{array}$} & \multirow[b]{2}{*}{$\begin{array}{l}\text { Quarterly data, } \\
6 \text { data points }{ }^{a} ; \\
\text { Range: } 2010-2011\end{array}$} & & iPad & & & iPad 2 & \\
\hline & & & $\begin{array}{l}\text { - } 6 \text { data points } \\
\text { - We use the sc } \\
\text { - iPad is the fir } \\
\text { - iPad discontir }\end{array}$ & $\begin{array}{l}\text { e used; } \\
\text { s data of the firs } \\
\text { generation of thi } \\
\text { ed after iPad } 2 w\end{array}$ & $\begin{array}{l}\text { vo generations of } \\
\text { roduct line; iPad } \\
\text { released in the } m\end{array}$ & $\begin{array}{l}\text { s product; } \\
\text { as first pre-ann } \\
\text { et; }\end{array}$ & din March 20 & \\
\hline
\end{tabular}


Table II: Model Fitting Results




Table III: Estimated Parameters

\begin{tabular}{|c|c|c|c|c|c|c|c|c|c|c|c|c|c|c|}
\hline \multirow{2}{*}{ Product } & \multirow{2}{*}{ Model } & & & & & & & & & & & & & \\
\hline & & 1 & 2 & 3 & 4 & 5 & 6 & 7 & $M_{1}$ & $M_{2}$ & $M_{3}$ & $M_{4}$ & $M_{5}$ & $M_{6}$ \\
\hline \multirow{5}{*}{$\begin{array}{c}\text { Nintendo } \\
\text { Home } \\
\text { Console }\end{array}$} & Proposed & $\begin{array}{c}0.13 \\
(0.02)\end{array}$ & $\begin{array}{c}0.77 \\
(<0.01)\end{array}$ & $\begin{array}{l}<0.01 * * \\
(<0.01)\end{array}$ & & & & & $\begin{array}{c}3.34 \mathrm{E}+04 \\
(9.74 \mathrm{E}+01)\end{array}$ & $\begin{array}{c}1.93 \mathrm{E}+04 \\
(7.60 E+01)\end{array}$ & $\begin{array}{c}8.35 E+04 \\
(1.40 E+02)\end{array}$ & & & \\
\hline & $N B$ & & & & & & & & & & & & & \\
\hline & $M M$ & 0.11 & 0.66 & & & & & & $\begin{array}{c}3.33 E+04 \\
368+01\end{array}$ & $\begin{array}{l}2.15 E+04 \\
3.15+E+01\end{array}$ & $\begin{array}{c}9.60 E+04 \\
-8.55+01\end{array}$ & & & \\
\hline & & $<0.01^{* *}$ & $<0.01^{* *}$ & 1.00 & & & & 3.46 & $2.20 \mathrm{E}+05$ & $1.09 \mathrm{E}+05$ & $1.44 E+05$ & & & \\
\hline & $J P$ & $(<0.01)$ & $(<0.01)$ & $(0.01)$ & & & & $(0.02)$ & $(4.66 \mathrm{E}+03)$ & $(1.47 E+03)$ & $(6.33 E+02)$ & & & \\
\hline \multirow{4}{*}{$\begin{array}{l}\text { Nintendo Home } \\
\text { Console } \\
\text { (GA Setting 2) }^{a}\end{array}$} & Proposed & $\begin{array}{l}1.2760 E-01 \\
(2.2855 E-06)\end{array}$ & $\begin{array}{l}7.7320 E-01 \\
(1.3307 E-05)\end{array}$ & $\begin{array}{l}\begin{array}{c}5.2743 E-06 \\
(5.7832 E-06)\end{array} \\
\end{array}$ & & & & & $\begin{array}{l}3.3389 E+04 \\
(5.7393 E-01)\end{array}$ & $\begin{array}{l}1.9283 E+04 \\
(2.8618 E-01)\end{array}$ & $\begin{array}{l}8.3512 E+04 \\
(8.6658 E-01)\end{array}$ & & & \\
\hline & IVD & 1.1301E-01 & $6.6265 \mathrm{E}-01$ & & & & & & $3.3261 \mathrm{E}+04$ & $2.1465 \mathrm{E}+04$ & $9.5991 \mathrm{E}+04$ & & & \\
\hline & $M M$ & $(1.43933 E-06)$ & $(8.6874 E-06)$ & & & & & & $(1.6655 \mathrm{E}-01)$ & (1.0108E-01) & $(3.4242 E-01)$ & & & \\
\hline & $J P$ & $\begin{array}{l}1.78288 E-06 \\
(1.6435 E-06)\end{array}$ & $\begin{array}{l}2.8453 E-06 \\
(3.2185 E-06)\end{array}$ & $\begin{array}{l}9.9759 \mathrm{E}-01 \\
(1.695 \mathrm{E}-05)\end{array}$ & & & & $\begin{array}{l}3.4567 飞+00 \\
(3.7510 E-05)\end{array}$ & $\begin{array}{l}2.2062 E+05 \\
(7.1147 F+00)\end{array}$ & $\begin{array}{l}1.0943 E+05 \\
(2.3520 E+00)\end{array}$ & $\begin{array}{l}1.44511+05 \\
(8.4877-01)\end{array}$ & & & \\
\hline \multirow{3}{*}{$\begin{array}{c}\text { Sony } \\
\text { Handheld } \\
\text { Console }\end{array}$} & $\begin{array}{c}\text { Proposed } \\
\text { NB }\end{array}$ & $\begin{array}{c}0.03 \\
(<0.01)\end{array}$ & $\begin{array}{c}0.13 \\
(<0.01)\end{array}$ & $\begin{array}{l}<0.01 * * \\
(<0.01)\end{array}$ & & & & & $\begin{array}{c}6.60 E+04 \\
(1.81 E+02)\end{array}$ & & & & & \\
\hline & $M M$ & $\begin{array}{c}0.04 \\
(<0.01)\end{array}$ & $\begin{array}{c}0.11 \\
(<0.01)\end{array}$ & & & & & & $\begin{array}{c}6.88 E+04 \\
(1.03 E+02)\end{array}$ & & & & & \\
\hline & $J P$ & $\begin{array}{c}0.10 \\
0<0101)\end{array}$ & & & & & & $\begin{array}{c}3.29 \\
(<0.01)\end{array}$ & $\begin{array}{r}6.28 E+04 \\
(9.66 E+01)\end{array}$ & & & & & \\
\hline \multirow{5}{*}{$\begin{array}{c}\text { Sony Home } \\
\text { Console }\end{array}$} & Proposed & $\begin{array}{c}0.01 \\
(<0.01) \\
(<0\end{array}$ & $\begin{array}{c}0.14 \\
(<0.01)\end{array}$ & $\begin{array}{l}<0.01^{* *} \\
(<0.01)\end{array}$ & & & & & $\begin{array}{c}1.07 \mathrm{E}+05 \\
(3.44 \mathrm{E}+02)\end{array}$ & $\begin{array}{l}1.29 E+05 \\
(6.83 E+02)\end{array}$ & & & & \\
\hline & $N B$ & & & & & & & & & & & & & \\
\hline & $M M$ & 0.02 & 0.13 & & & & & & $1.07 E+05$ & $1.38 \mathrm{E}+05$ & & & & \\
\hline & NIVI & $(<0.01)$ & $(<0.01)$ & & & & & & $(3.09 E+02)$ & $(8.70 E+02)$ & & & & \\
\hline & $J P$ & $\begin{array}{c}0.03 \\
(<0.01)\end{array}$ & $\begin{array}{c}0.14 \\
(0.01)\end{array}$ & & & & & $\begin{array}{l}4.78 \\
(0.09)\end{array}$ & $\begin{array}{c}3.45 E+05 \\
(1.37 E+04)\end{array}$ & $\begin{array}{c}2.30 \mathrm{E}+05 \\
(1.36 \mathrm{E}+03)\end{array}$ & & & & \\
\hline \multirow{7}{*}{$\begin{array}{c}\text { Microsoft } \\
\text { Home } \\
\text { Console }\end{array}$} & & 0.08 & 0.44 & 0.22 & & & & & $7.82 \mathrm{E}+04$ & $4.50 \mathrm{E}+04$ & & & & \\
\hline & Proposed & $(<0.01)$ & $(<0.01)$ & $(0.02)$ & & & & & $(5.11 E+03)$ & $(2.01 \mathrm{E}+03)$ & & & & \\
\hline & $N B$ & 0.56 & 0.90 & & & & & & $5.30 \mathrm{E}+03$ & $4.32 \mathrm{E}+03$ & & & & \\
\hline & & $(<0.01)$ & $(0.01)$ & & & & & & $(1.44 E+00)$ & $(1.44 E+00)$ & & & & \\
\hline & $M M$ & $\begin{array}{c}0.02 \\
(<0.01)\end{array}$ & $\begin{array}{l}0.19 \\
0.011\end{array}$ & & & & & & $\begin{array}{l}2.61 E+05 \\
(5.86 E+04)\end{array}$ & $\begin{array}{c}6.95 E+05 \\
(1.60 E+05\end{array}$ & & & & \\
\hline & & 0.75 & $\begin{array}{l}0.49 \\
0.49\end{array}$ & & & & & 2.84 & $2.51 \mathrm{E}+04$ & $8.10 \mathrm{E}+04$ & & & & \\
\hline & $J P$ & $(0.01)$ & $(0.02)$ & & & & & $(0.02)$ & $\begin{array}{l}(9.80 E+01) \\
\end{array}$ & $\begin{array}{l}(1.37 E+03) \\
(1.03\end{array}$ & & & & \\
\hline \multirow{7}{*}{ Apple PC } & Proposed & 0.03 & 0.04 & 0.05 & & & & & $1.81 \mathrm{E}+04$ & $5.94 \mathrm{E}+03$ & $1.44 E+04$ & $1.77 \mathrm{E}+04$ & $2.58 \mathrm{E}+04$ & $3.28 \mathrm{E}+04$ \\
\hline & & $(0.01)$ & $(0.01)$ & $(0.01)$ & & & & & $(2.42 E+03)$ & $(1.07 E+03)$ & $(2.38 E+03)$ & $(2.94 E+03)$ & $(4.28 E+03)$ & $(5.53 E+0)$ \\
\hline & $N B$ & & & & & & & & & & & & & \\
\hline & $M M M$ & 0.06 & 0.17 & & & & & & $7.02 E+03$ & $4.67 E+03$ & $9.63 E+03$ & $1.61 \mathrm{E}+04$ & $2.67 \mathrm{E}+04$ & $3.81 E+04$ \\
\hline & $M M$ & $(0.01)$ & $(0.02)$ & & & & & & $(3.17 E+02)$ & $(7.53 E+02)$ & $(1.58 E+03)$ & $(2.57 E+03)$ & $(3.87 E+03)$ & $\begin{array}{c}(5.70 E+03 \\
)\end{array}$ \\
\hline & $J P$ & 0.16 & $<0.01^{* *}$ & 0.37 & 0.10 & 0.07 & 0.09 & 2.83 & $6.45 \mathrm{E}+03$ & $1.27 \mathrm{E}+04$ & $1.32 \mathrm{E}+04$ & $2.15 \mathrm{E}+04$ & $3.05 E+04$ & 4. $23 E+04$ \\
\hline & $J r$ & $(0.04)$ & $(<0.01)$ & $(0.09)$ & $(0.02)$ & $(0.02)$ & $(0.02)$ & (0.18) & $(6.13 E+02)$ & $(1.00 E+03)$ & $(1.26 E+03)$ & $(2.00 E+03)$ & $(3.09 E+0)$ & $(4.39 E+0)$ \\
\hline \multirow{5}{*}{$\begin{array}{c}\text { Apple Tablet } \\
\text { Computer }\end{array}$} & Proposed & $\begin{array}{c}0.04 \\
(0.01)\end{array}$ & $\begin{array}{c}0.61 \\
(0.03)\end{array}$ & $\begin{array}{l}0.26 \\
(0.01)\end{array}$ & & & & & $\begin{array}{c}7.04 \mathrm{E}+04 \\
(9.76 E+03)\end{array}$ & $\begin{array}{c}1.97 E+05 \\
(3.45 E+04)\end{array}$ & & & & \\
\hline & $N B$ & $\begin{array}{c}0.17 \\
(<0.01)\end{array}$ & $\begin{array}{l}<0.01 \\
(<0.01)\end{array}$ & & & & & & $\begin{array}{c}5.53 E+03 \\
<<0.01 E+0 \\
0\end{array}$ & $\begin{array}{l}7.17 E+03 \\
(6.64 E-01)\end{array}$ & & & & \\
\hline & $M M$ & 0.14 & 0.57 & & & & & & $2.60 \mathrm{E}+04$ & 6.35E+04 & & & & \\
\hline & Frivi & $\begin{array}{l}(0.01) \\
0.99\end{array}$ & $\begin{array}{l}(0.02) \\
2.70\end{array}$ & & & & & 2.97 & $\begin{array}{l}(1.27 E+03 \\
2.111+04\end{array}$ & $\begin{array}{l}(5.48 E+03 \\
4.07+04\end{array}$ & & & & \\
\hline & $J P$ & $(0.10)$ & $\begin{array}{l}2.10 \\
(0.24)\end{array}$ & & & & & $(0.23)$ & $\begin{array}{r}2.111+044 \\
(3.72 E+02)\end{array}$ & $\begin{array}{c}4.00 \mathrm{E}+04 \\
(3.04 E+02)\end{array}$ & & & & \\
\hline \multirow{7}{*}{$\begin{array}{c}\text { Apple Smart } \\
\text { Phone }\end{array}$} & & 0.03 & 0.38 & 0.26 & & & & & $3.74 \mathrm{E}+04$ & $1.66 \mathrm{E}+05$ & $7.22 E+04$ & $2.54 \mathrm{E}+05$ & & \\
\hline & Proposed & $(<0.01)$ & $(0.04)$ & $(0.04)$ & & & & & $(6.02 E+03)$ & $(3.22 E+04)$ & $(2.49 E+04)$ & $(3.37 E+04)$ & & \\
\hline & $N B$ & $\begin{array}{c}1.13 \\
(<0.01)\end{array}$ & $\begin{array}{l}<0.01 \\
1<0.011\end{array}$ & & & & & & 1.40E+03 & $4.08 E+03$ & 3.11E+03 & $9.70 E+03$ & & \\
\hline & & & $\begin{array}{l}(<0.01) \\
0.25\end{array}$ & & & & & & $(4.06 E+00)$ & $(7.30 E+00)$ & $(6.49 E+00)$ & $(5.68 E+00)$ & & \\
\hline & $M M$ & $\begin{array}{l}.0 .07 \\
(0.01)\end{array}$ & $\begin{array}{l}0.25 \\
(0.03)\end{array}$ & & & & & & $\begin{array}{l}1.48 E+04 \\
(2.22 E+03)\end{array}$ & $\begin{array}{c}6.94 E+04 \\
(1.22 E+04)\end{array}$ & $\begin{array}{l}8.52 E+04 \\
(1.41 F+041\end{array}$ & $\begin{array}{r}2.28 E+05 \\
(4.62+044\end{array}$ & & \\
\hline & IP & 0.96 & $<0.01^{* * *}$ & 0.20 & 0.62 & & & 3.42 & $6.60 \mathrm{E}+03$ & $\begin{array}{l}1.225+044 \\
1.74 \mathrm{E}+05\end{array}$ & 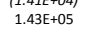 & $\begin{array}{l}14.025+44) \\
1.65 E+05\end{array}$ & & \\
\hline & $J P$ & $(0.05)$ & $(<0.01)$ & $(0.03)$ & $(0.06)$ & & & $(0.12)$ & $(1.31 E+02)$ & $(2.05 E+04)$ & $(6.58 E+03)$ & $(8.40 E+03)$ & & \\
\hline \multirow{6}{*}{$\begin{array}{c}\text { Apple } \\
\text { Portable } \\
\text { Media Player }\end{array}$} & & 0.03 & $<0.01^{* * *}$ & 0.35 & & & & & $7.60 \mathrm{E}+05$ & $7.91 E+05$ & $7.91 \mathrm{E}+05$ & $7.33 \mathrm{E}+05$ & $6.39 \mathrm{E}+05$ & \\
\hline & Proposed & $(<0.01)$ & $(<0.01)$ & $(<0.01)$ & & & & & $(1.08 E+05)$ & $(1.14 E+05)$ & $(1.14 E+05)$ & $(1.07 E+05)$ & $(9.31 E+04)$ & $\stackrel{(8.13 E+04}{)}$ \\
\hline & $N B$ & & & & & & & & & & & & & \\
\hline & $M M$ & & & & & & & & & & & & & \\
\hline & & $<0.01 * *$ & $<0.01^{* *}$ & $<0.01^{* *}$ & $<0.01^{* *}$ & $<0.01^{* *}$ & $<0.00^{* *}$ & 0.95 & $5.15 \mathrm{E}+04$ & $1.07 E+05$ & $1.62 E+05$ & $2.16 \mathrm{E}+05$ & $2.65 \mathrm{E}+05$ & $3.07 \mathrm{E}+05$ \\
\hline & $J P$ & $(<0.01)$ & $(<0.01)$ & $(<0.01)$ & $(<0.01)$ & $(<0.01)$ & $(<0.01)$ & $(0.05)$ & $(2.57 E+03)$ & $(3.93 E+03)$ & $(4.83 E+03)$ & $(5.52 E+03)$ & $(5.84 E+03)$ & $(5.88 E+03$ \\
\hline in parentheses & andard & ins of th & 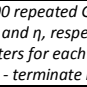 & , thents & & mo & Signi & 0.05 & $\operatorname{sign}$ & $\begin{array}{l}\text { tat }<0.01 \\
\text { vely; in the } \\
\text { erations. }\end{array}$ & iodel, $p c$ & $r 7$ & ty $p a$ & or non- \\
\hline
\end{tabular}


Table IV: Forecasting Performance

\begin{tabular}{|c|c|c|c|c|c|c|c|c|c|c|c|c|c|c|}
\hline \multicolumn{4}{|c|}{ CP 8 (points), 1 point ahead } & \multicolumn{2}{|c|}{ CP 8,2 points ahead } & & \multicolumn{2}{|c|}{ CP 9, 1 point ahead } & \multicolumn{3}{|c|}{ SUM \& Rank } & & & \\
\hline Microsoft & Proposed & $29.46 \%$ & Microsoft & Proposed & $60.33 \%$ & Microsoft & Proposed & $0.17 \%$ & Microsoft & Proposed & $89.96 \%(3)$ & & & \\
\hline Home & $N B$ & $26.62 \%$ & Home & NB & $20.18 \%$ & Home & NB & $10.49 \%$ & Home & $N B$ & $57.29 \%(1)$ & & & \\
\hline \multirow[t]{2}{*}{ Console } & MM & $61.09 \%$ & Console & MM & $109.82 \%$ & Console & MM & $43.65 \%$ & Console & MM & $214.56 \%(4)$ & & & \\
\hline & & $23.11 \%$ & & $J P$ & $35.00 \%$ & & $J P$ & $0.13 \%$ & & $J P$ & $58.24 \%(2)$ & & & \\
\hline \multirow{4}{*}{$\begin{array}{c}\text { Nintendo } \\
\text { Home } \\
\text { Console }\end{array}$} & \multicolumn{2}{|c|}{ CP 13,1 point ahead } & & \multicolumn{2}{|c|}{ CP 13, points ahead } & \multirow[b]{2}{*}{$\begin{array}{c}\text { Nintendo } \\
\text { Home }\end{array}$} & \multicolumn{2}{|c|}{ CP 14, 1point } & \multicolumn{3}{|c|}{ SUM \& Rank } & & & \\
\hline & \multicolumn{2}{|l|}{$\begin{array}{c}\text { Proposed } \\
\text { NB }\end{array}$} & $\begin{array}{c}\text { Nintendo } \\
\text { Home }\end{array}$ & $\begin{array}{l}\text { Proposed } \\
N B\end{array}$ & $72.69 \%$ & & $\begin{array}{c}\text { Proposed } \\
\text { NB }\end{array}$ & $17.69 \%$ & $\begin{array}{c}\text { Nintendo } \\
\text { Home }\end{array}$ & $\begin{array}{c}\text { Proposed } \\
\text { NB }\end{array}$ & $\begin{array}{r}101.26 \% \text { (1) } \\
\text { (4) }\end{array}$ & & & \\
\hline & $M M$ & $52.06 \%$ & Console & MM & $101.85 \%$ & Console & $M M$ & $22.27 \%$ & Console & $M M$ & $176.18 \%(2)$ & & & \\
\hline & $J P$ & $71.20 \%$ & & $J P$ & $98.58 \%$ & & $J P$ & $70.94 \%$ & & $J P$ & $240.72 \%(3)$ & & & \\
\hline & CP 16, 1 & nt ahead & & CP 16, p & $s$ ahead & & CP 17 & & & SUM & Rank & & & \\
\hline & Proposed & $8.97 \%$ & & Proposed & $2.55 \%$ & & Proposed & $7.04 \%$ & & Proposed & $18.56 \%(1)$ & & & \\
\hline Apple & $N B$ & $15.11 \%$ & Apple & $N B$ & $1.25 \%$ & Apple & $N B$ & $12.52 \%$ & Apple & $N B$ & $28.88 \%(2)$ & & & \\
\hline & $M M$ & $8.97 \%$ & & $M M$ & $10.92 \%$ & & MM & $22.03 \%$ & & MM & $41.92 \%$ (4) & & & \\
\hline & $J P$ & $2.54 \%$ & & $J P$ & $12.93 \%$ & & $J P$ & $18.02 \%$ & & $J P$ & $33.49 \%(3)$ & & & \\
\hline & CP 45, 1 & nt ahead & & CP 45, 2 & ts ahead & & $\mathrm{CP} 45,3$ & $s$ ahead & & CP 45, 4 & nts ahead & & CP 46, 1 & $t$ ahead \\
\hline & Proposed & $5.41 \%$ & Anple PC & Proposed & $15.17 \%$ & Apple PC & Proposed & $0.69 \%$ & Anple PC & Proposed & $8.98 \%$ & Apple PC & Proposed & $15.17 \%$ \\
\hline Apple PC & $\begin{array}{l}N B \\
M M\end{array}$ & $6.55 \%$ & & $M M$ & $10.46 \%$ & & $M M$ & $7.38 \%$ & & $\begin{array}{l}N B \\
M M\end{array}$ & $20.66 \%$ & & $\begin{array}{l}N B \\
M M\end{array}$ & $12.69 \%$ \\
\hline & $J P$ & $10.19 \%$ & & $J P$ & $6.10 \%$ & & $J P$ & $10.44 \%$ & & $J P$ & $22.22 \%$ & & $J P$ & $14.71 \%$ \\
\hline & $\mathrm{CP} 46,2 \mathrm{~F}$ & tts ahead & & $\mathrm{CP} 46,3$ & ts ahead & & CP 47,1 & $t$ ahead & & $\mathrm{CP} 47,2$ & nts ahead & & CP 48,1 & $t$ ahead \\
\hline & Proposed & $0.69 \%$ & & Proposed & $8.98 \%$ & & Proposed & $3.23 \%$ & & Proposed & $13.20 \%$ & & Proposed & $8.98 \%$ \\
\hline Apple PC & $N B$ & & Apple PC & $N B$ & & Apple PC & NB & & Apple PC & $N B$ & & Apple PC & $N B$ & \\
\hline & $M M$ & $5.51 \%$ & & $M M$ & $19.14 \%$ & & $M M$ & $8.17 \%$ & & $M M$ & $21.44 \%$ & & $M M$ & $19.67 \%$ \\
\hline & $J P$ & $2.47 \%$ & & $J P$ & $15.22 \%$ & & $J P$ & $8.64 \%$ & & $J P$ & $20.87 \%$ & & $J P$ & $18.06 \%$ \\
\hline & sum & Rank & & & & & & & & CP 5, 1 & nt ahead & & SUN & \\
\hline & Proposed & $80.50 \%(1)$ & & & & & & & Apple & Proposed & $1.19 \%$ & Apple & Proposed & $1.19 \%(1)$ \\
\hline Apple PC & $N B$ & (4) & & & & & & & Tablet & $N B$ & $34.39 \%$ & Tablet & $N B$ & $34.39 \%(4)$ \\
\hline & $M M$ & $131.67 \%$ (3) & & & & & & & Computer & $M M$ & $1.25 \%$ & Computer & $M M$ & $1.25 \%(2)$ \\
\hline & $J P$ & $128.92 \%$ (2) & & & & & & & & $J P$ & $29.78 \%$ & & $J P$ & $29.78 \%(3)$ \\
\hline & CP 22, 1 & nt ahead & & CP 22, 2 & ts ahead & & CP 23, 1 & ahead & & SUM & Rank & & & \\
\hline & Proposed & $16.49 \%$ & Apple & Proposed & $3.80 \%$ & $\begin{array}{c}\text { Apple } \\
\text { Pos }\end{array}$ & Proposed & $10.17 \%$ & $\begin{array}{c}\text { Apple } \\
\text { Pon }\end{array}$ & Proposed & $30.46 \%(1)$ & & & \\
\hline Portable & $N B$ & & Portable & $N B$ & & Portable & $N B$ & & Portable & $N B$ & (3) & & & \\
\hline Media & $M M$ & & Media & $M M$ & & Media & $M M$ & & Media & $M M$ & (3) & & & \\
\hline & $J P$ & $14.90 \%$ & & $J P$ & $5.86 \%$ & & $J P$ & $10.44 \%$ & & $J P$ & $31.20 \%(2)$ & & & \\
\hline & CP 14, 4p & its ahead & & CP 14,8 & ts ahead & & CP 18,4 & $s$ ahead & & SUM & Rank & & & \\
\hline Sony & Proposed & $38.33 \%$ & Sony & Proposed & $82.89 \%$ & Sony & Proposed & $61.42 \%$ & Sony & Proposed & $182.64 \%(1)$ & & & \\
\hline Handheld & $N B$ & & Handheld & $N B$ & & Handheld & $N B$ & & Handheld & $N B$ & (4) & & & \\
\hline Console & $M M$ & $38.17 \%$ & Console & $M M$ & $82.81 \%$ & Console & $M M$ & $62.94 \%$ & Console & $M M$ & $183.92 \%(2)$ & & & \\
\hline & $J P$ & $64.39 \%$ & & $J P$ & $98.25 \%$ & & $J P$ & $79.98 \%$ & & $J P$ & $242.62 \%(3)$ & & & \\
\hline & CP 38, 4p & ts ahead & & CP 38, 8 & ts ahead & & CP 38, 12 & ts ahead & & CP 42, 4 & nts ahead & & CP 42, 8 & ts ahead \\
\hline & Proposed & $237.97 \%$ & Sonv Home & Proposed & $30.83 \%$ & Sonv Home & Proposed & $33.24 \%$ & Sonv Home & Proposed & $28.36 \%$ & Sonv Home & Proposed & $33.82 \%$ \\
\hline Console & $N B$ & & Console & $N B$ & & Console & $N B$ & & Console & $N B$ & & Console & $N B$ & \\
\hline & MM & $264.81 \%$ & & $M M$ & $47.08 \%$ & & MM & $32.64 \%$ & & MM & $36.16 \%$ & & $M M$ & $29.38 \%$ \\
\hline & $J P$ & $98.02 \%$ & & $J P$ & $99.77 \%$ & & $J P$ & $100.00 \%$ & & $J P$ & $83.50 \%$ & & $J P$ & $99.19 \%$ \\
\hline & CP $46,4 p$ & its ahead & & sun & lank & & & & & & & & & \\
\hline & & $33.13 \%$ & & & $397.35 \%(1)$ & & & & & & & & & \\
\hline Sony Home & $N B$ & & Sony Home & $N B$ & (4) & & & & & & & & & \\
\hline & MM & $27.92 \%$ & & $M M$ & $437.99 \%(2)$ & & & & & & & & & \\
\hline & $J P$ & $68.56 \%$ & & $J P$ & $549.04 \%(3)$ & & & & & & & & & \\
\hline
\end{tabular}


Figure 1: MGPD Processes
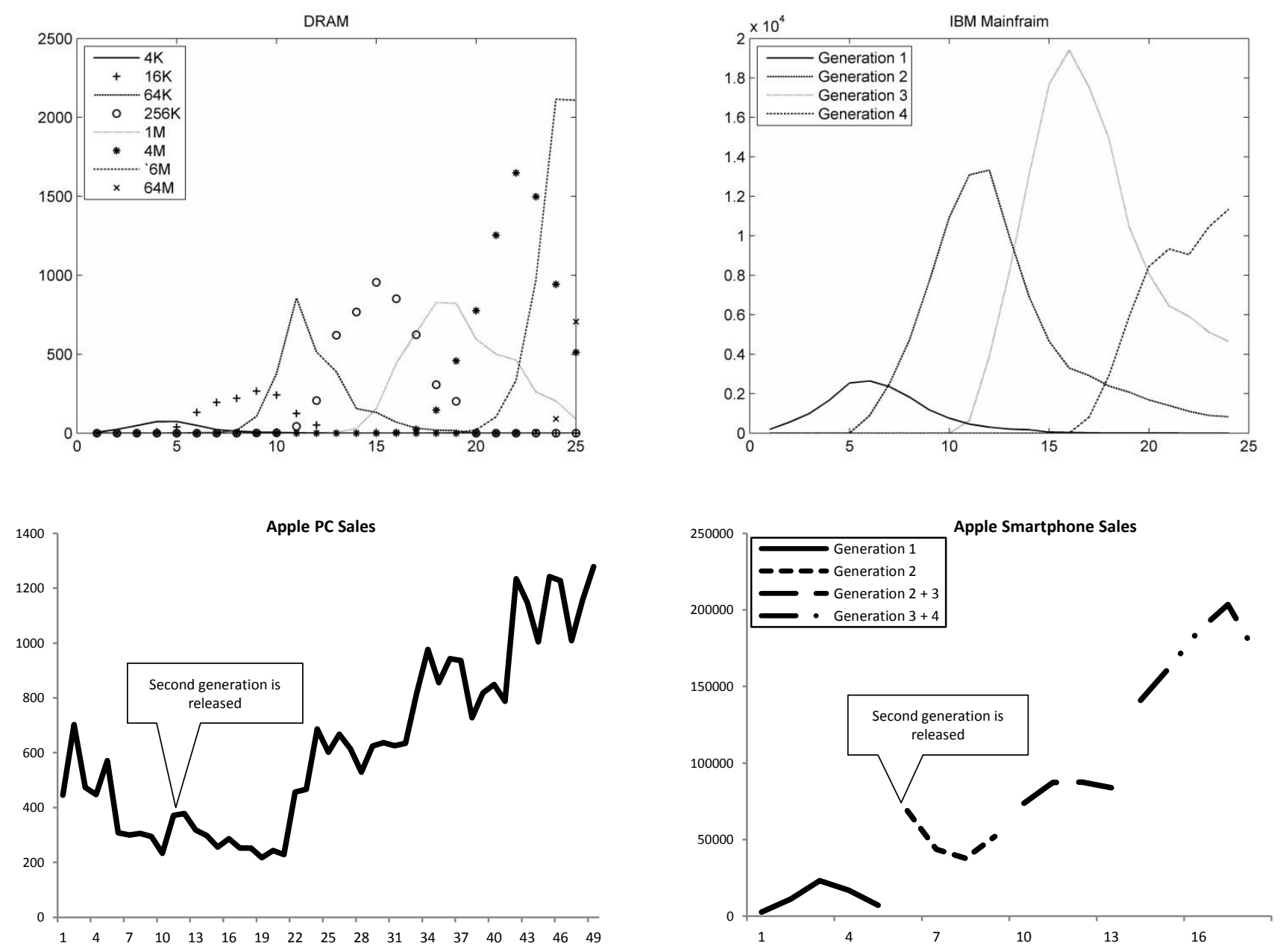
Figure 2: Estimation Results
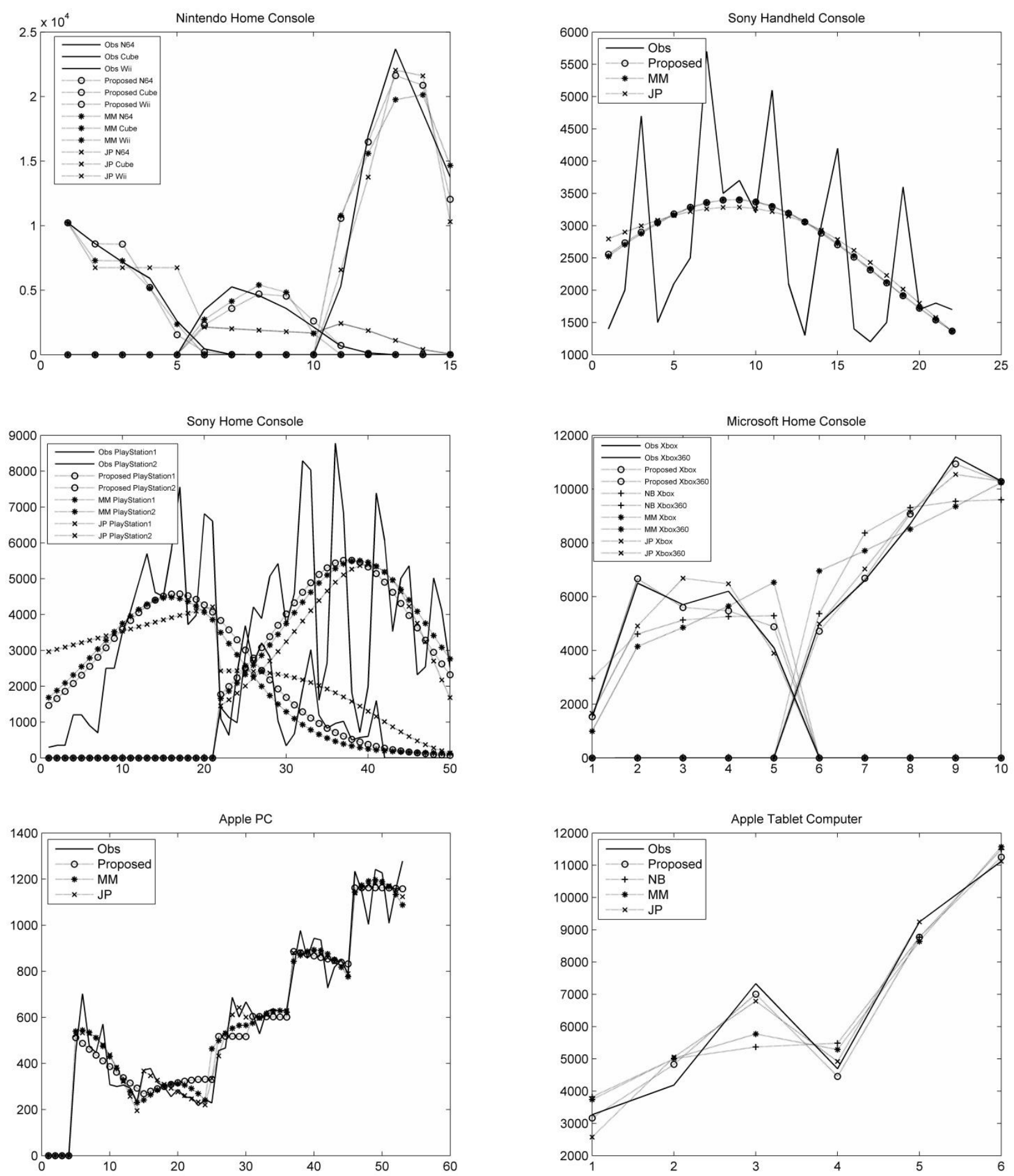

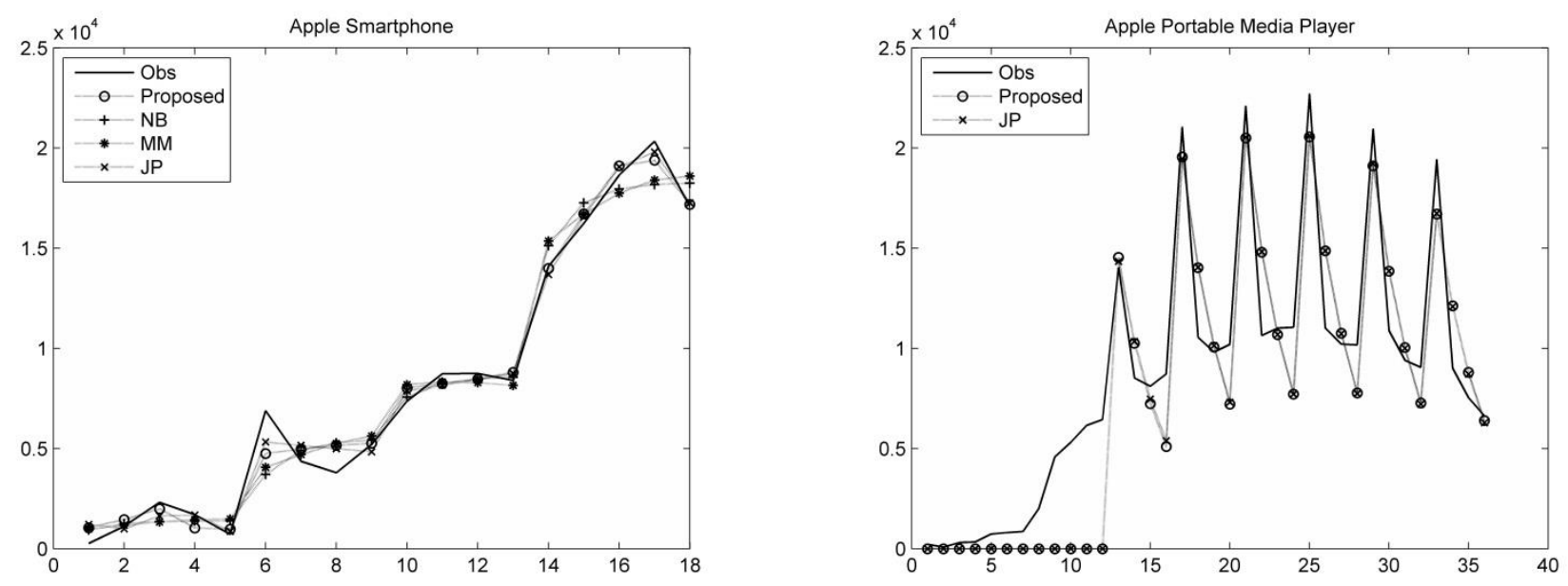

Figure 3: Performance of Proposed Model I and II
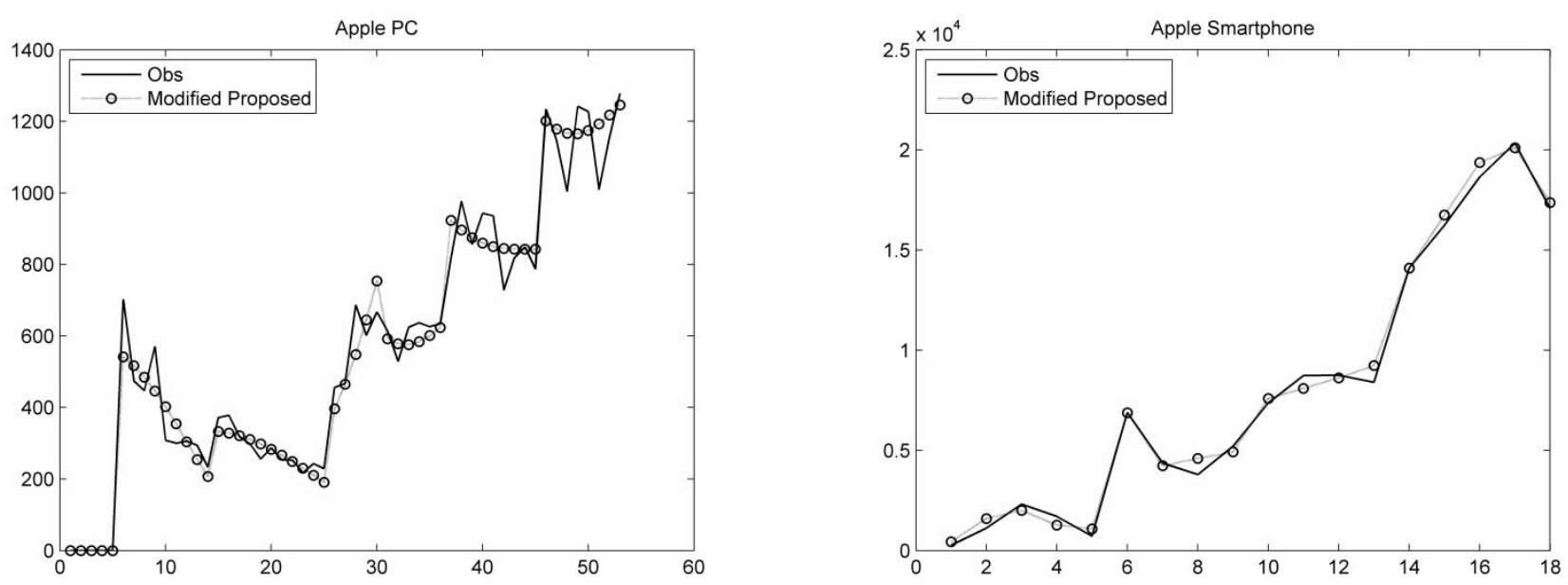

Figure 4: Forecasting Performance for Microsoft Home Console

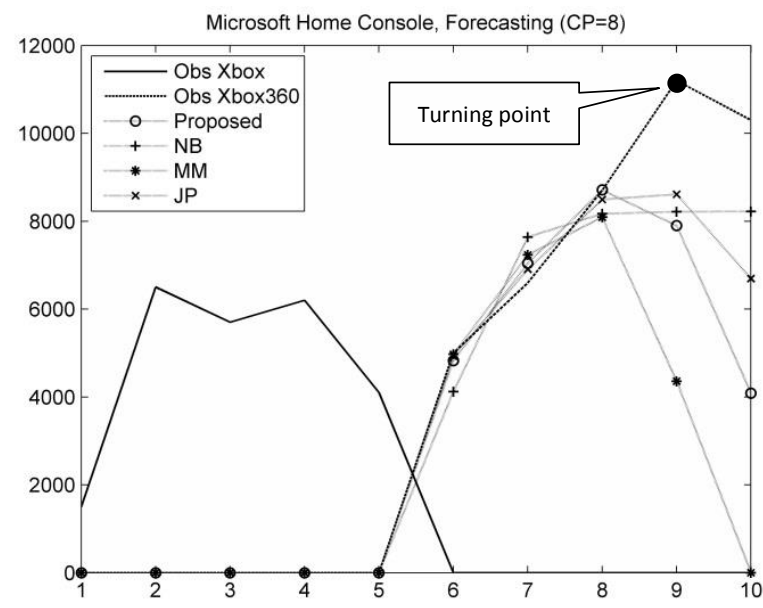

